\title{
EL CINE, RECURSO FORMATIVO. 18 AÑOS DE INVESTIGACIÓN DEL GRUPO GIAD
}

\section{THE CINEMA, AN EDUCATIONAL RESOURCE. 18 YEARS OF RESEARCH BY GIAD GROUP}

\author{
Dra. Mª Luisa Sevillano García ${ }^{1}$ \\ mlsevillano@edu.uned.es \\ Dr. Saturnino de la Torre de la Torre ${ }^{2}$ \\ sentipensar@yahoo.es \\ Carlos Carreras $\mathrm{Nadal}^{2}$ \\ carreras@filnet.es
}

(1) Universidad Nacional de Educación a Distancia (UNED). Facultad de Educación.Departamento de Didáctica, Organización Escolar y Didácticas Especiales. Juan del Rosal,14 28040, Madrid (España)

${ }^{(2)}$ Universidad de Barcelona. Facultad de Formación del Profesorado Passeig de la Valld'Hebron, 171 08035, Barcelona (España)

Tras una referencia a los antecedentes históricos del cine en el ámbito educativo, se reflexiona sobre el papel del cine en la escuela y como instrumento de transmisión de valores. El cine es un instrumento moldeable de forma que puede ser utilizado tanto para el adoctrinamiento político como para la formación ciudadana. Se analiza la experiencia del cine formativo a lo largo de 18 años en la universidad de Barcelona, conducido por el grupo GIAD. El mensaje central del trabajo se centra en el cine como trasmisor de valores y como recurso dinámico y escénico acorde con planteamientos propios del pensamiento complejo y mirada transdisciplinar. Proporciona una formación en contenidos y estrategias para aprender del medio. El cine permite educar en valores, siendo al tiempo un escenario didáctico polivalente. Palabras clave: Cine formativo, experiencia innovadora, modelo ORA, cine en la universidad.

A review of the cinema in the educational field shows the importance of cinema in the school for transmitting values. The educational cinema experience during 18 years at the University of Barcelona, driven by the GIAD group, is analysed. The central message of this work focuses on the cinema to transmit moral values, and as a dynamic resource that generates complex thoughts and transdisciplinary point of views. The cinema provides singular educational content and strategies to learn from the environment. In addition, the cinema allows moral values transmission and a polyvalent didactic scenario.

Keywords: Educational films, innovative experience, ORA model, films in the university. 


\section{Antecedentes del cine educativo.}

La experiencia y consiguiente investigación sobre el cine formativo en la universidad surge puntualmente como una forma de conmemorar el centenario de la primera proyección cinematográfica en 1995. El grupo de GIAD de la Universidad de Barcelona, decide, a partir del éxito logrado, continuar celebrando durante el mes de noviembre ciclos de una semana de proyecciones, conferencias, debates, mesas redondas en torno a temáticas pedagógicas ilustradas con películas comerciales. Así es como surge el Seminario permanente de Cine Formativo en el que participan profesores de diversos departamentos de Ciencias de la Educación y posteriormente se incorpora alumnado interesado en la temática. Pero lo más novedoso de esta iniciativa no es tanto las semanas de cine, que lo son, sino los seminarios y reuniones formativas para debatir y prepararse en temáticas pioneras, retadoras, de puntas de lanza en una pedagogía de nuestros días. La dimensión educativa y el aprovechamiento formativo han acompañado al cine desde sus orígenes. En 1898 el Dr. Doyen proyectaba películas para sus alumnos. En 1912 el Ministerio de Agricultura galo introduce el cine para la formación profesional y en 1921 ya es valorado como medio de enseñanza e instrucción por la mayoría de personas vinculadas a la enseñanza pública y privada. Francia fue pionera en estos primeros pasos. El movimiento cooperativo Célestin Freinet también ha dedicado especial atención al cine. Desde 1984 se ha puesto en marcha un sistema completo que permite integrar el cine en las actividades culturales y educativas de los estudiantes franceses.

En 1922 la Asociación de Educación Nacional de los Estados Unidos nombra un co- mité para estudiar el cine y su uso escolar, aunque las conclusiones no fueron muy motivadoras. Un nuevo estudio, esta vez con profesores universitarios de Columbia y Chicago aportó unas expectativas más positivas. Pronto hubo 32 de los 48 Estados con filmotecas dirigidas por pedagogos. En el bloque de la URSS comenzó con mucho entusiasmo. Se obligó a proyectar cortos y programas culturales. En 1930 habían hecho 300 películas educativas, con 3000 copias cada una. En 1935 había 12000 cines ambulantes y 4112 salas fijas.

En Alemania, el gobierno apoyó pronto la producción de películas culturales, para que los maestros pudieran seleccionar aquellas películas que pudieran ayudarles en su labor docente. A partir de 1934, pasa a ser controlado y potenciado por los nazis. En un principio, se da preferencia a las películas mudas, para no sustituir las explicaciones de los maestros. En Austria, se crea el cine escolar al final de la $1^{\text {a }}$ Guerra Mundial. En 1925 se funda la Liga Cinematográfica Escolar, con apoyo del gobierno desde 1928, que llegó a ser una potente productora de cine didáctico.

En Italia se crea, en 1924, l'Unione Cinematografica Educativa. En 1928, el gobierno italiano institucionaliza el Instituto Internacional del Cine. En 1929 el cine llega a la escuela. En 1999, el Ministerio de Educación ha financiado el Plan Nacional para la Promoción de la Didáctica del Lenguaje Cinematográfico y Audiovisual en la Escuela, aunque la inestabilidad de los gobiernos lo ha ralentizado.

En España, el primer documento oficial a favor del uso del cine, aparece en 1912 en el Boletín Oficial del Ministerio de Instrucción Pública, a partir del cual se comienzan a adquirir aparatos de proyección destinados a la enseñanza. Sin embargo, sólo se toma en se- 
rio en Cataluña y en los municipios de Bilbao y San Sebastián con las Misiones Pedagógicas, que habían producido 156 películas en 1931, llegando a 411 en 1934. La Escuela de Cine comienza en los años 40. En Cataluña se establecieron, entre 1931 y 1939 , los fundamentos de la primera industria cinematográfica. En 1932 se crea el Comité de Cine, y entre 1932 y 1934 se introduce el cine en la Escuela Primaria. El hecho de que los países y gobiernos recurran al cine como instrumento de difusión de sus políticas nos muestra hasta qué punto representa un instrumento de cambio social. Resaltamos aquí su valor positivo y constructivo, pero somos conscientes de que también destruye valores morales al promover, por ejemplo, valores (mejor llamarlos contra-valores) de bajo rango como consumo, sexo, violencia, enfrentamientos, instinto de poder... El cine es un medio seductor, fascinante, y no son pocos los educadores e instituciones que lo utilizan como recurso habitual en la instrucción.

\section{El cine en publicaciones españolas.}

Recientemente contamos con varias publicaciones en revistas de enfoque pedagógico como Comunicar, Aularia, Pixel-Bit. Contrasta la escasa importancia que adquiere en las revistas educativas el valor formativo del cine con la relevancia social y recreativa del mismo. Tal vez sea la revista Comunicar la que más se ha ocupado de difundirlo. En 1998 aparece un monográfico «Educar en los medios» en el que se aborda la utilización del cine en la enseñanza a través de una veintena de artículos: cine en la enseñanza de Historia, de Filosofía, Poesía, el aprendizaje del cine, pasando por historia del cine, disfrutar del cine o una clase de cine. Los medios, afirma el coordinador, han de estar al servicio de la mejora de la calidad de la educación. El segundo monográfico que dedica la revista comunicar al cine aparece en 2007 bajo el titulo «La enseñanza del cine en la era de las multipantallas». Se analiza la enseñanza del cine en diferentes sistemas educativos europeos (Francia, Gran Bretaña, Italia, Holanda, España, entre otros), para profundizar en el análisis fílmico y la metodología de la enseñanza. ¿Qué sentido tiene la incorporación del cine en la enseñanza universitaria? Desde luego tiene un sentido cultural y educativo, a decir de J. Marzal, coordinador de este número, pero también didáctico a nuestro entender. Es un recurso que permite ilustrar y clarificar conceptos abriendo un debate sobre los mismos. Sin embargo, la conclusión a la que llega es que, a pesar de la aparente relevancia, no ha logrado instalarse en los currícula con sentido formativo, tal como viene haciendo el grupo GIAD de la Universidad de Barcelona. Además de estos monográficos cabe mencionar los trabajos publicados en dicha revista por MartínezSalanova (2003) y Clarembeaux (2010).

En Aularia, revista digital sobre educomunicación, con apenas tres años de vida, encontramos títulos como: Importancia del cine en la educación, cine y educación, el cine y la educación para la ciudadanía, cine y audiovisuales para la educomunicación. Interesa el cine como tema de debate.

La revista Píxel-Bit, de enfoque más técnico sobre medio y educación, ha publicado el trabajo de Moreno (1996) «El guión y la tecnología de producción de cine, TV y video», diferenciando varios tipos de guiones (literario, de trabajo, técnico) y unidades narrativas como la toma, el plano, escenas, secuencias. Pero se abordan también cuestiones educativas como el trabajo de Bonilla (2005) sobre el cine y los valores educativos, utili- 
zando el cine como instrumento para educar en valores en la ESO. El cine con perspectiva de género, tiene potencia educadora.

Recogemos algunas ideas expresadas por Bonilla. Los medios de comunicación en general y el cine en particular son poderosos recursos de influencia y transformación educativa y social. De hecho, tanto el cine como la TV son medios a disposición de los políticos y sus ideologías, consiguiendo transformar la opinión pública como podemos constatar fácilmente en España. Para Bonilla (2005, p. 40), citando a Loscertales, el cine tiene un doble valor: a) Como espejo de esa sociedad, reproduciendo los estereotipos; b) como generadora de modelos tanto en las claves de valores e ideologías como en las pautas actitudinales. Dos orientaciones: el cine como herramienta didáctica y como instrumento para educar en valores (Torre, 1998).

Para concluir este apartado es preciso mencionar las diversas publicaciones realizadas por el grupo GIAD de la Universidad de Barcelona (Torre et al., 1996, 1998, 1999, 2005) fruto de las experiencias llevadas a cabo en el ámbito universitario, en el que se enmarca este artículo. «Se justifica así, la importancia del cine como recurso didáctico y metodología de nuevos diseños curriculares, dentro de los cuales contaría con gran relevancia el tratamiento de los valores educativos» (Bonilla, 2005, p. 40).

\section{Pensamiento pedagógico y educación en valores.}

Entre las edades de 3 y 5 años, muchos niños/as se familiarizan con personajes populares de la televisión y el cine orientados a los niños pequeños. El primer acercamiento del bebé a la propia cultura (lengua, costumbres, actos o conmemoraciones,...) lo hace con frecuencia a través de la televisión mediante dibujos animados, relatos, filmes y anuncios que son los espacios que más les estimulan. El cine es un momento de sueños.

El cine comienza en casa, como primer entorno de aprendizaje, sigue en la escuela como apoyo curricular y continúa en las salas de cine y en la pequeña pantalla ya sea a través de DVD o de emisiones en TV. A ello hemos de añadir el seguimiento de emisiones vía Internet. La televisión (y el cine), a decir de RRPPnet (2010), es un vehículo de control. Es el símbolo de la cultura de masas.

El cine es una historia narrada a través de imágenes en movimiento. Es por ello que el cine tiene unas peculiaridades como estrategia didáctica que lo hacen atractivo, sugestivo e implicativo, para aprender. Estamos ante un medio que sobrepasa los métodos instructivos y ofrece un valioso recurso para educar en valores, creencias, creatividad, ética y pautas sociales. El cine mиеve y conтиеve. Hace pensar, sentir, reaccionar. Es como una gran ventana a la vida de los niños, que les muestra lo próximo y distante, real e imaginario. Es fantasía, pero también realidad. Su fascinación es colocar al espectador ante posiciones y dilemas morales que invitan a la reflexión.

Drac Magic es una entidad, dedicada al estudio y divulgación de los audiovisuales. Sus programaciones son adaptables a las diferentes niveles educativos desde educación primaria como apoyo a las enseñanzas de las diferentes áreas o temáticas culturales. Para Solà y Selva (1996), los niños y niñas llegan al aula con otra cultura televisiva e informática que reflejan la aldea transaccional en la que vivimos, marcada por valores económicos y publicitarios. Incorpora el placer como forma de conocimiento. «El saber no es contradictorio con el gozar, sino que incrementa 
su capacidad, en contra de lo que se plantea convencionalmente» (o.c.: 48). Para Drac Magic el cine como lugar de encuentro de una pluralidad de lenguajes ofrece la oportunidad de ser propuesto como síntesis de diferentes manifestaciones de expresión humana: icónica, gestual, verbal, musical.

Pero el cine es ante todo un escenario para educar en valores. «El cine ha afectado a todos los niveles de la vida, a la que ha dado una dilatación fabulosa, nunca antes soñada: ha sido el más eficaz instrumento de paideia, y con un alcance universal» Marías (Citado por Mallart \& Solaz, 2005, p. 80). No son pocos los autores que se suman a esta visión del cine como instrumento pedagógico al servicio de los valores y la solidaridad.

La utilización del cine como instrumento de formación en valores estimula la capacidad crítica del alumnado, al tiempo que refuerza su bagaje cultural y promueve aprendizajes integrados. El cine va más allá de la palabra integrando imagen, música, acción, interacciones en un relato. Porque en toda película subyace como estructura básica el relatar una historia. Y eso siempre resulta atractivo y motivante para quienes viven en la era digital y de la imagen.

El trabajo de Mallart y Solaz (2005) recoge un amplio programa para trabajar valores dentro del aula, realzando el valor educativo del cine. «La vida cotidiana, prosaica y sencilla, se convierte en una maravillosa fantasía de aventuras que no podríamos vivir de otra manera. Recibimos mensajes positivos ante la existencia que nos hace vislumbrar valores y maneras de actuar distintos de los que observamos en lo cotidiano» (De la Torre, Pujol $\&$ Rajadell 2005, p.81). Incluso en las películas de aventuras podemos encontrar extraordinarios valores humanos, de relación, convivencia y ayuda.
Autores como Salvat (citado por Mallart \& Solaz, 2005, p.83) propone una lectura ética y de valores humanos y sociales junto a la tradicional lectura fílmica. Entre los valores que dicho autor sugiere están: respecto a la dignidad de la persona, el valor de la verdad, responsabilidad, justicia, equidad y solidaridad, libertad y derecho a la intimidad humanidad, honestidad y sinceridad.

\section{Diseño metodológico.}

\subsection{Hipótesis general.}

El cine comercial se puede transformar en una estrategia didáctica innovadora en la universidad

\subsection{Objetivos.}

- Buscar alternativas de mejoras en la enseñanza universitaria. Describir el proceso de aprendizaje y cambio innovador en la enseñanza universitaria a través del cine.

- Constatar y contrastar la evolución de las temáticas, de la participación e implicación de profesorado y alumnado generando un modelo de interacción didáctica y de aprendizaje.

- Comprobar si el cine comercial puede ser utilizado en la formación universitaria como una estrategia didáctica innovadora para la transmisión de conocimientos y valores humanos.

\subsection{Recogida de información y muestra.}

La información aquí utilizada se ha obtenido mediante la participación en el programa por parte del profesorado implicado, coordinando algunas de las sesiones. Por lo que respecta a los estudiantes a través de la ins- 
cripción de créditos de libre elección y entrega de certificaciones, previos a cada edición (Véase Gráfica 1). Cada año se ha elaborado un dossier con las películas que se proyectaban siguiendo el modelo ORA (Observa, Reflexiona, Aplica). Ha sido un promedio de 1012 películas por año.

Por lo que respecta a informaciones de carácter cualitativo, se ha obtenido de las actas de las reuniones del Seminario de Cine Formativo, los programas editados en cada edición y dossier a disposición de los estudiantes, el documento de la inauguración que marcaba las directrices y las conclusiones presentadas en las clausuras de cada semana de cine formativo. Las informaciones cuantitativas y cualitativas recogidas son las que fundamentan las consideraciones y conclusiones finales.

Tiene lugar en el Campus de Ciencias de la Educación de la Universidad de Barcelona

- El personal implicado son miembros de GIAD, del Seminario, expertos invitados, Instituciones universitarias desde el Vicerrectorado a los departamentos.
- Las temáticas son relevantes por cuanto generan debate y formación.

Reconocimiento de créditos de libre elección que juegan un papel fundamental en los aprendizajes.

\subsection{Instrumentos.}

Modelo ORA. Al analizar y comentar las películas, el modelo descrito en la obra «Estrategias de simulación» (1997), es fruto de una investigación sobre estrategias didácticas en entornos no académicos, utilizando la simulación como principal referente. En tal sentido tanto las lecturas como las dramatizaciones y películas se prestan a ser analizadas didácticamente siguiendo los tres momentos: Observar, Reflexionar y Aplicar. Aplicado el modelo a las películas, se pedía al estudiante que tomara en consideración estos conceptos y secuencias.

\subsection{Implementación.}

Cada jornada ha ido precedida de reuniones formativas, y acompañada de un tríptico en el que se glosaba el significado y sentido

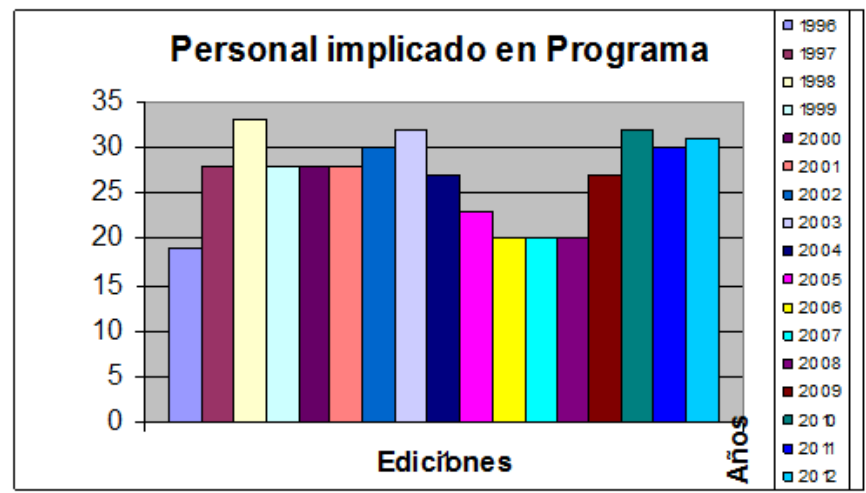

Gráfica 1. Personal implicado en el programa y ediciones. $-92-$

Píxel-Bit. Revista de Medios y Educación. No 46. Enero 2015. ISSN: 1133-8482. e-ISSN: 2171-7966. doi: http://dx.doi.org/10.12795/pixelbit.2015.i46.06 
de la temática. Sintetizamos la formalización metodológica de este largo proceso de dieciocho años en los siguientes puntos. Los miembros que conforma el Seminario de Cine formativo mantienen reuniones para profundizar en problemáticas poco usuales en los planes de estudio vigentes. A veces invitando a expertos.

A partir de la X edición (2004) el grupo comienza a adentrarse en un nuevo paradigma a través del aprendizaje integrado y cuestiones como la transdisciplinariedad, la ecoformación y la conciencia que tienen lugar en años posteriores. El grupo GIAD y el Seminario de Cine comienzan a marcar una visión teórica que va más allá del cine. El Pensamiento complejo y la transdisciplinariedad están presentes en proyectos competitivos de investigación. Las jornadas van a servir para trascender la reflexión pedagógica dominante y adoptar en la investigación y en la enseñanza una nueva mirada. Los intereses comunitarios y sociales van desplazando a cuestiones meramente académicas.

La procedencia y vinculación del personal implicado en la organización y desarrollo podría agruparse en tres núcleos:

a) El grupo estable perteneciente al grupo GIAD y que tenía un papel más comprometido con la preparación y desarrollo de la semana. Era el núcleo principal del Seminario de Cine que contaba con unos diez miembros, aunque la implicación y responsabilidades iban cambiando.

b) Quienes conformaban el Seminario de Cine pero no pertenecían al grupo, sino que eran profesores de otras áreas y estudiantes interesados en el cine o en la temática de ese año.

c) Personas invitadas para conferencias, mesas redondas o para dinamizar las sesiones de debate que seguía a la proyección.
Entre estos grupos agradecemos la participación desinteresada de la Escuela Superior de Cinematografía de Cataluña (ESCAC) y ocasionalmente DracMagic.

Los principios psicopedagógicos que sustentan dicho modelo son (Torre et. al., 1997, p. 39): partir de la realidad más próxima, simular la realidad cuando ésta no sea accesible, desarrollar la observación y análisis, el aprendizaje como proceso sociocognitivo, la reflexión como motor de cambio, ampliación de significados e intereses, relación teoría-práctica, facilitar la transferencia de los aprendizajes a otros contextos. Estos principios otorgan un nuevo sentido al procedimiento transformando la información en formación.

\subsection{Temporalización}

El periodo analizado va desde 1995 a 2012 (18 años).

No son pocos los ciclos de cine que las más diversas instituciones promueven para resaltar valores ya sean nacionales o patrios, culturales o espirituales con interés humano, formativo e incluso de abordaje de cuestiones históricas, linguuísticas, filosóficas, éticas, etc. Un ejemplo de los primeros son los ciclos de cine organizados por las Embajadas en diferentes países para promover valores nacionales o regionales. Otros son los ciclos de contenido científico, cultural, espiritual, de salud o formativo como es el organizado ininterrumpidamente desde 1995 por el Grupo GIAD de la universidad de Barcelona dirigido a estudiantes universitarios. Además de ir explorando temáticas pedagógicas relevantes, el alumnado debate en público y reflexiona a través de memorias de aprendizaje. De eso nos ocupamos con más detalle en este artículo. 
La utilización de películas o documentales en el aula puede ser considerada como situación o recurso curricular que promueve escenarios ecoformativos. El visionado del film en el aula y posterior comentario docente, debate y trabajo por parte de los alumnos, crea espacios de diálogo, interacción, propicios para desarrollar actitudes y valores. Basta utilizar un procedimiento adecuado como el modelo ORA, descrito por el grupo GIAD (1996, 1998, 1999, 2005). Como bien apunta Ortiz (2008) trabajar con imágenes como las de la TV y el cine permite educar la mirada, entendiendo que lo que no forma, puede deformar, porque conscientes o inconscientes de ello influye. Es preciso «Educar la mirada para un consumo saludable de los contenidos» Ortiz (2008, p. 10). Toda imagen en movimiento lleva un mensaje que procesa nuestro cerebro. Por eso resulta tan importante tomar conciencia de los nuevos medios audiovisuales e informáticos.

En la obra del grupo GIAD «El cine, un entorno educativo» (2005) se desarrollan las temáticas que durante diez años trabajaron en las semanas de cine formativo. Ofrece un abanico de posibilidades educativas y didáctica y pone de manifiesto el potencial de este recurso audiovisual que en cierto modo complementa a la informática. A través del cine podemos abordar problemáticas y planteamientos pedagógicos, psicopedagógicos, éticos, filosóficos, psicológicos, sociales, históricos, lingüísticos, jurídicos y de cualquier otra disciplina académica y formativa. El cine es conocimiento.

\section{Resultados.}

Presentamos a continuación algunos resultados destacando tres puntos principalmente
1) La exploración de temáticas pedagógicas. Innovación docente

2) El reconocimiento académico

3) El Modelo ORA y los aprendizajes alcanzados.

\subsection{Temáticas y aspectos preferentes en el cine de proyección didáctica.}

Sirva de referencia la temática de la transdisciplinariedad como profundización en las temáticas que se elegían cada año (Véase Cuadro 1). En cada una buscábamos varias dimensiones o facetas que luego se iban trabajando cada uno de los días de la semana.

a) La trans como actitud y por tanto como actitud de ver y entender el cine.

b) Como acción humana y formativa en particular (ecoformación), por tanto se fija en la interacción o acción dinámica entre los elementos y no en el sujeto, el objeto o el contexto.

c) Como metodología de conocimiento, como epistemología o mirada sobre la realidad, en cuyo caso cabe tener en cuenta tres conceptos: Los niveles de percepción, conciencia y realidad, la complejidad.

\subsection{El reconocimiento académico de cré- ditos.}

Para obtener la certificación el alumnado inscrito debía asistir al acto de inauguración con conferencia y al menos a cinco actos (mesa redonda, cortos, proyecciones) a lo largo de la semana y presentar una memoria de aprendizajes. Dichas memorias eran valoradas por el profesorado participante de modo que si no había evidencias suficientes de aprovechamiento no se otorgaba la certificación. En número de estudiantes que se acogían a esta oferta académica era muy variable 


\begin{tabular}{|c|c|c|}
\hline AÑOS & TEMÁTICA/ & ASPECTOS A RESALTAR \\
\hline 1995-I & Dimensión formativa & Temática general con la participación de Directores de programas de TV \\
\hline 1996-II & $\begin{array}{l}\text { Comunicación } \\
\text { educativa }\end{array}$ & Diferentes aspectos de la Comunicación \\
\hline 1997-III & Formación y cambio & Se analizan cambios personales, instituciones y sociales a través del cine \\
\hline 1998-IV & $\begin{array}{l}\text { Formación } \quad y \\
\text { Conflicto }\end{array}$ & Se analizan los conflictos y como resolverlos a través del cine \\
\hline 1999-V & Impacto & Se aborda por primera vez la importancia del Impacto en los aprendizajes \\
\hline 2000-VI & Creatividad & Se estudia el tema de la creatividad a través de las películas \\
\hline 2001-VII & Emociones & Se estudia la dimensión emocional a través de la observación de películas \\
\hline 2002-VIII & Diversidad & Se estudia la diversidad en sus múltiples manifestaciones a través del cine \\
\hline 2003-IX & Resiliencia & Se explora esta temática nueva mediante la visualización y debate de películas \\
\hline 2004-X & $\begin{array}{l}\text { Aprendizaje } \\
\text { integrado }\end{array}$ & $\begin{array}{l}\text { En la décima edición se aborda la temática del aprendizaje integrados dando } \\
\text { pié a un primer congreso que permite una primera panorámica de los diez años. }\end{array}$ \\
\hline 2005-XI & Transdisciplinariedad & Se explora por primera vez la mirada transdisciplinar a través de películas \\
\hline 2006-XII & Ecoformación & Se explora por primera vez el alcance de la ecoformación a través de películas \\
\hline 2007-XIII & Convivencia & $\begin{array}{l}\text { Se explora la problemática de la indisciplina escolar y la convivencia a través } \\
\text { del cine }\end{array}$ \\
\hline 2008-XIV & Conciencia & Se explora por primera vez la temática de la conciencia a través del cine \\
\hline 2009-XV & Los derechos del niño & $\begin{array}{l}\text { Coincidiendo con los } 50 \text { años de la Declaración universal de los derechos del } \\
\text { niño se dedica esta semana a explorar los diferentes derechos mediante } \\
\text { películas }\end{array}$ \\
\hline 2010-XVI & Los 7 saberes & $\begin{array}{l}\text { Tomando como base la obra de E. Morin Los } 7 \text { saberes se analizan películas } \\
\text { para abordar y profundizar en la temática }\end{array}$ \\
\hline 2011-XVII & conflictos sociales & Se analizan los conflictos sociales y educativas a través de películas \\
\hline 2012- & Recursos humanos & Se focaliza el estudio y análisis en los recursos humanos a través del cine \\
\hline
\end{tabular}

Cuadro 1. Temáticas y aspectos preferentes en el cine didáctico. 


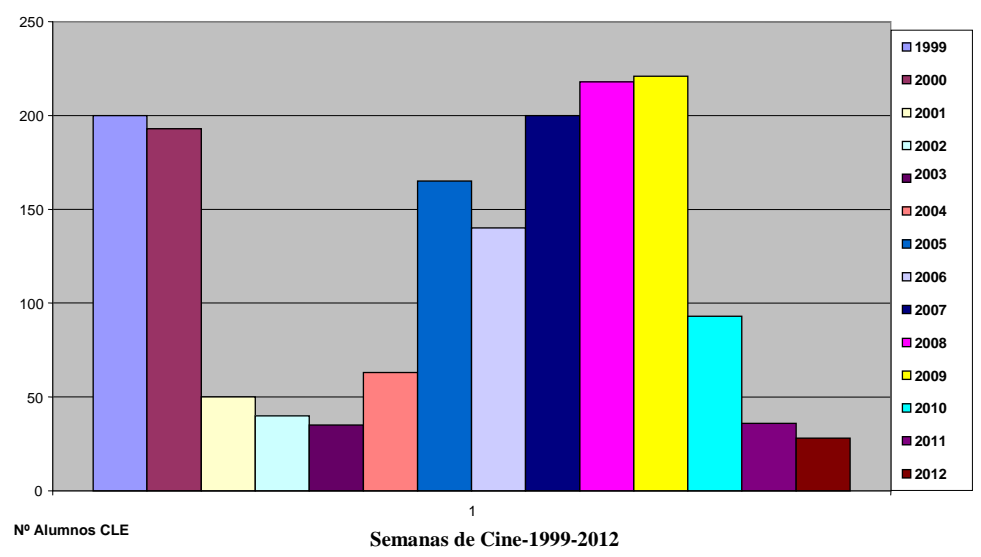

Gráfica 2. Créditos de libre elección.

de un año a otro, teniendo prioridad los de cursos superiores. Estamos hablando de una oferta fuera de la carga horaria del profesorado implicado por cuanto siempre se ha realizada por propia voluntad de los miembros del grupo GIAD.

El alumnado siempre ha valorado muy positivamente esta oferta por cuanto era un aprendizaje de libre iniciativa e interés además de motivante y estimulante para la reflexión pedagógica y la práctica en entornos formativos. Se le proporcionaba un instrumento de análisis útil como era el modelo ORA del que luego hablaremos.

La implantación del reconocimiento de crédito se inicia en 1999. El alumnado interesado asistirá al menos a seis de las sesiones de la Semana de Cine Formativo y al finalizar la semana entregará un trabajo en el que se ponga de manifiesto los aprendizajes logrados (Véase Gráfica 2).

Estas informaciones evidencian el impacto que ha venido teniendo las jornadas de cine formativo, en la autoformación del profesorado implicado en las semanas, en los aprendizajes del alumnado, en la búsqueda de nue- vos escenarios innovadores para la enseñanza. La incorporación de metodologías más flexibles, dinámicas y participativas. Estos tres créditos que se otorgaban permitieron que algunos estudiantes pudieran acabar su carrera.

El modelo ORA está presente en las seis obras sobre cine que el grupo GIAD ha publicado $(1996,1998,1999,2005,2011,2012)$ y en las películas comentadas. Estas publicaciones son la mejor evidencia de los excelentes resultados de esta iniciativa formativoinnovadora de la enseñanza universitaria. Integra la formación académica con la extraacadémica y al tiempo que pone en práctica nuevos recursos, reflexiona sobre ellos y permite que otros los utilicen y los transfieran a sus propios contextos. Se da respuesta a inquietudes conceptuales y de aplicación. El análisis de estos trabajos suscita las siguientes consideraciones y aprendizajes alcanzados:

a) Que son trabajos realizados de forma colaborativa y grupal. Este es un mensaje que caracteriza al Seminario desde el inicio. 
b) El carácter innovador de la propuesta didáctica y metodológica. Esta actividad ha estado vinculada a la enseñanza más que a la investigación como expresión de una inquietud innovadora. Tanto los encuentros como las publicaciones están centradas en la docencia y orientadas a los estudiantes, buscando en ello escenarios didácticos innovadores.

c) Pone de manifiesto una evolución del Grupo por lo que respecta a la fundamentación teórica y a las temáticas abordadas. Se abordan cuestiones escasamente tratadas en los programas formales que no tardan en trasladarse a las aulas. Impacto, Resiliencia, Transdisciplinariedad, Ecoformación, son temáticas nuevas.

d) Estamos ante un grupo abierto, diverso y heterogéneo por cuanto participan personas de áreas diferentes y está abierto a alumnos y colaboradores. No son pocos los estudiantes que han participado tanto en la organización y gestión de los encuentros como en las publicaciones fomentando de ese modo la interacción docente.

\section{Consideraciones y conclusiones deri- vadas del estudio.}

Problemáticas como el conflicto y la crisis, el impacto como estrategia didáctica, la creatividad, la resiliencia son poco conocidos en ese momento. Las semanas de cine van a contribuir a profundizar, pero también a concienciar y difundir dichas cuestiones en la formación del alumnado universitario.

Uno de los conceptos más relevantes de la mirada transdisciplinar es la conciencia. Puede ser tan amplio que tienda a confundir. Diferenciando la conciencia humana de cualquier otra más natural o biológica, sería como focalizar la atención sobre algo, hacerlo relevante, destacado, significativo.

Las 18 jornadas de cine formativo organizadas por el Grupo GIAD en la Universidad de Barcelona (1995-2012) han permitido explorar temáticas psicopedagógicas como la resiliencia, el conflicto, aprendizaje integrado, el impacto, interculturalidad, creatividad, ecoformación, transdisciplinariedad...Nos han ayudado a profundizar en otras temáticas como la comunicación, las emociones, la diversidad, las relaciones familia-escuela, los derechos de la infancia. Con ello queremos mostrar el enorme potencial del cine para dar una formación docente ecoformadora y transdisciplinar. El cine nos permite adentrarnos en conceptos como la vida y la muerte, la conciencia, la trascendencia, la ética y valores, las creencias y todo aquello que traspasa las fronteras de la ciencia actual.

El carácter innovador de la enseñanza y la renovación pedagógica ha sido sin duda el principio inspirador y eje central de las Semanas de cine formativo. Una innovación que ha precisado de formación, de disposición al cambio, de exploración de nuevas temáticas psicopedagógicas. Se han utilizado las películas comerciales como recurso, el cambio de escenario como estrategia y las nuevas temáticas como reflexión pedagógica. A través de esta dinámica se han fomentado los valores humanos, sociales, medioambientales, trascendentes, éticos y profesionales. Se constata esta toma de conciencia a través de los comentarios realizados en las memorias de aprendizaje. Ese es el aprendizaje logrado.

Se ha movilizado a las instituciones universitarias: a la Administración para que lleve a cabo el reconocimiento de créditos, a los jefes de estudios de las diferentes enseñanzas psicopedagógicas, a los docentes de te- 
máticas diferentes. Pero dicha acción no queda reducida al ámbito académico sino que ha sido una oportunidad para conectar con otras entidades del entorno, que han venido colaborando habitualmente, como el Colegio Oficial de Doctores y Licenciados, el ESCAC, Drac Magic, entre otras.

Un beneficio de gran utilidad para los estudiantes ha sido el reconocimiento de créditos de libre elección. Ello ha representado una dedicación complementaria al profesorado sin otra compensación que la satisfacción del alumnado. Pero este reconocimiento lleva ya en si la semilla de un aprendizaje integrador al pedirle observar y analizar, reflexionar y relacionar, aplicar y transferir lo aprendido. Se ha rescatado la dimensión emocional como complemento a la formación intelectual. Los debates han permitido hacer conscientes los mensajes subliminales que los medios de comunicación de masas como el cine, televisión, publicidad, trasmiten.

Confirmamos que los procesos cognitivos y de socialización están fuertemente influenciados por variables estructurales determinadas, jugando el cine un papel relevante en este proceso. Cine y televisión son potentes trasmisores de emociones, actitudes y valores (Fernández, Revilla \& Domínguez 2011).No en vano afirmaba Jean-LucGodard que el cine es un instrumento de pensamiento original que está a medio camino entre la filosofía, la ciencia y la literatura (Hirsch 2011).

El cine como estrategia permite crear escenarios de enseñanza-aprendizaje que se sitúan en un nuevo paradigma del pensamiento complejo. En la dinámica que se genera a partir de una proyección resulta difícil quedar al margen del grupo sin expresar lo que uno piensa, siente, espera o desea como resultado de la situación vivenciada. Se des- piertan las emociones y con ellas se movilizan ideas y actuaciones.

\section{Agradecimientos.}

Apoyos recibidos de tipo logístico, material y moral de la Universidad de Barcelona y sus instituciones (Facultades, Departamentos, ARCE, Centro de Recursos), a los tres coordinadores: S. de la Torre (1995-2003), $\mathrm{M}^{\mathrm{a}}$ Pujol (2004-2009) y N. Rajadell (2010-2014).

\section{Referencias bibliográficas.}

Actas e informes internos del grupo GIAD relativas a las Semanas de Cine Formativo. Barcelona. Dpto DOE de la Universidad de Barcelona.

Bonilla J. (2005). El cine y los valores educativos. Píxel-Bit. Revista de Medios y Educación, 26,39-54.

Clarembeaux, M. (2010). Educación en Cine; memoria y patrimonio. Comunicar, XVIII (20), 25-32.

Fernández, C., Revilla, J.C \& Domínguez, R. (2011). Las emociones que suscita la violencia en la televisión. Comunicar, XVIII (36), 95-105.doi:10.3916/C36-2011-02-10

Fernández, F., Sánchez, X.\& Villarroel, G. (1997). Influencias de la exposición a la televisión de los escolares. Comunicar, 8, 117127.

Hirsch, S. (2011). Jean-Luc Gordard. http:/ /www.inventodeldemonio.es/2011/03/jeanluc-godard-un-encargado-para-la-misión-dela-búsqueda-científica.html

Mallart, J. \& Solaz. C. (2005). Cine y educación en valores. En S. Torre y otros (Coords.). El cine, un entorno educativo (pp. 75-92). Madrid: Narcea. 
Martínez-Salanova, E. (2003). El valor del cine para aprender y enseñar. Comunicar, 20, 45-52.

Moreno, J.L. (1996). El guión y la tecnología de producción en cine, televisión y video. Píxel-Bit. Revista de Medios y Educación, 7, 29-45.

Ortiz, M. A. (2008). Educar la mirada en la «Sociedad multipantalla». Comunicar, XVI (31),10-20. doi:10.3916/c31-2008-01-001

Revista Comunicar (1998), 11. Monográfico Educar en los medios.

Revista Comunicar (2007), 29. Monográfico: El cine en la era de las multipantallas.

Torre, S. (Coord) (1977). Estrategias de simulación. ORA, un modelo innovador para aprender del medio. Barcelona: Octaedro.

Torre, S. (Coord.) (1996).Cine formativo. Barcelona: Octaedro.

Torre, S. (Coord.) (1998). Cine para la vida. Formación y cambio en el cine. Barcelona: Octaedro.

Torre, S. (Coord.) (1999). Aprender del conflicto en el cine. Barcelona: PPU.

Torre, S. Pujol, M. A. \& Rajadell, N. (Coords.) (2005). El cine, un entorno educativo Diez años de experiencias a través del cine. Madrid: Narcea. 


\section{ANEXO-1 PELÍCULAS PROYECTADAS durante las 15 primeras semanas}

\begin{tabular}{|c|c|}
\hline $\begin{array}{l}\text { I SETMANA DE CINEMA FORMATIU - 1995“EI } \\
\text { cinema forma” }\end{array}$ & $\begin{array}{l}\text { VII SETMANA DE CINEMA FORMATIU - } \\
\text { 2001“Emocions i cinema formatiu” }\end{array}$ \\
\hline El señor de las moscas.Matar a un ruiseñor & En lo profundo del océano \\
\hline Chicos de la calleEl pequeño Tate & Billy Elliot (Quiero bailar)El bola \\
\hline ForrestGumpEl rey leónTod y Toby & La ciudad de la alegríaEl corazón del guerrero \\
\hline Tierras de penumbra & Cadena de favoresTreitumLa colecciónChocolatMi mapa \\
\hline II SETMANA DE CINEMA FORMATIU - & del mundoMemento \\
\hline 1996"Cinema i comunicació educativa" & You'retheoneChickenrun \\
\hline Un lugar en el mundo.El guardián de las & VIII SETMANA DE CINEMA FORMATIU - \\
\hline palabrasNellProfesor Holland, Pena de muerte & 2002"Diversidad i cinema formatiu" \\
\hline Amigas para siempre, Historias del Konen & littel Senegal, Elling , Farenheit 451 \\
\hline Mentes peligrosasEl señor de los anillos & El milagro de Anna Sullivan, GostWorld \\
\hline III SETMANA DE CINEMA FORMATIU -1997““ & El hijo de la noviaTierra de nadie, Shek \\
\hline Formació i canvi en el cinema" & Gosford Park, En construcción \\
\hline El jorabado de Notre Dame, El octavo día, & IX SETMANA DE CINEMA FORMATIU - 2003 \\
\hline Todas las mañanas del mundo, La estrategia del caracol, & "Resiliència i cinema formatiu" \\
\hline Sostiene PereiraEl cartero (Pablo Neruda)Tesis, Diario & A propósito de SchmidtLa casa de mi vida \\
\hline de un rebeldeSmoke & Casa de locos, Los 400 golpes, Kamtchatka \\
\hline IV SETMANA DE CINEMA FORMATIU - & Balzac y la joven costurera chinaEl aceite de la vida \\
\hline 1998“Formació i conflicte en el cinema" & (Lorenzo'soil), Elling, Amélie \\
\hline Persiguiendo a Amy Secretos del corazón & Bowling forColumbine \\
\hline Mejor....imposible, Full Monty, Carícies & X SETMANA DE CINEMA FORMATIU - \\
\hline In and Out, Taxi, Peraustrina 2004 & 2004"Aprenentatge integrat $i$ cinema formatiu" \\
\hline V SETMANA DE CINEMA FORMATIU - & El nombre de la rosa, Elephant, Cleopatra \\
\hline 1999"Imacte i cinema formatiu" & El señor de las moscas, El festín de Babette \\
\hline El chow de TrumanEl indomable Will Hunting & Las mujeres tienen curvas, La vida de nadie \\
\hline Patch Adams, Estación central de Brasil & Animal Factory, Memento, Billy Elliot (Quiero bailar), El \\
\hline Marnie la ladrona, Mis vacaciones i Endora & Bola, Jóvenes prodigiosos \\
\hline Gattca, American History X, Cosas que dejé en La & Las cenizas de Angélica, Las razones de mis amigos?, \\
\hline Habana, Barrio, Lavida es bella & You'retheone \\
\hline
\end{tabular}




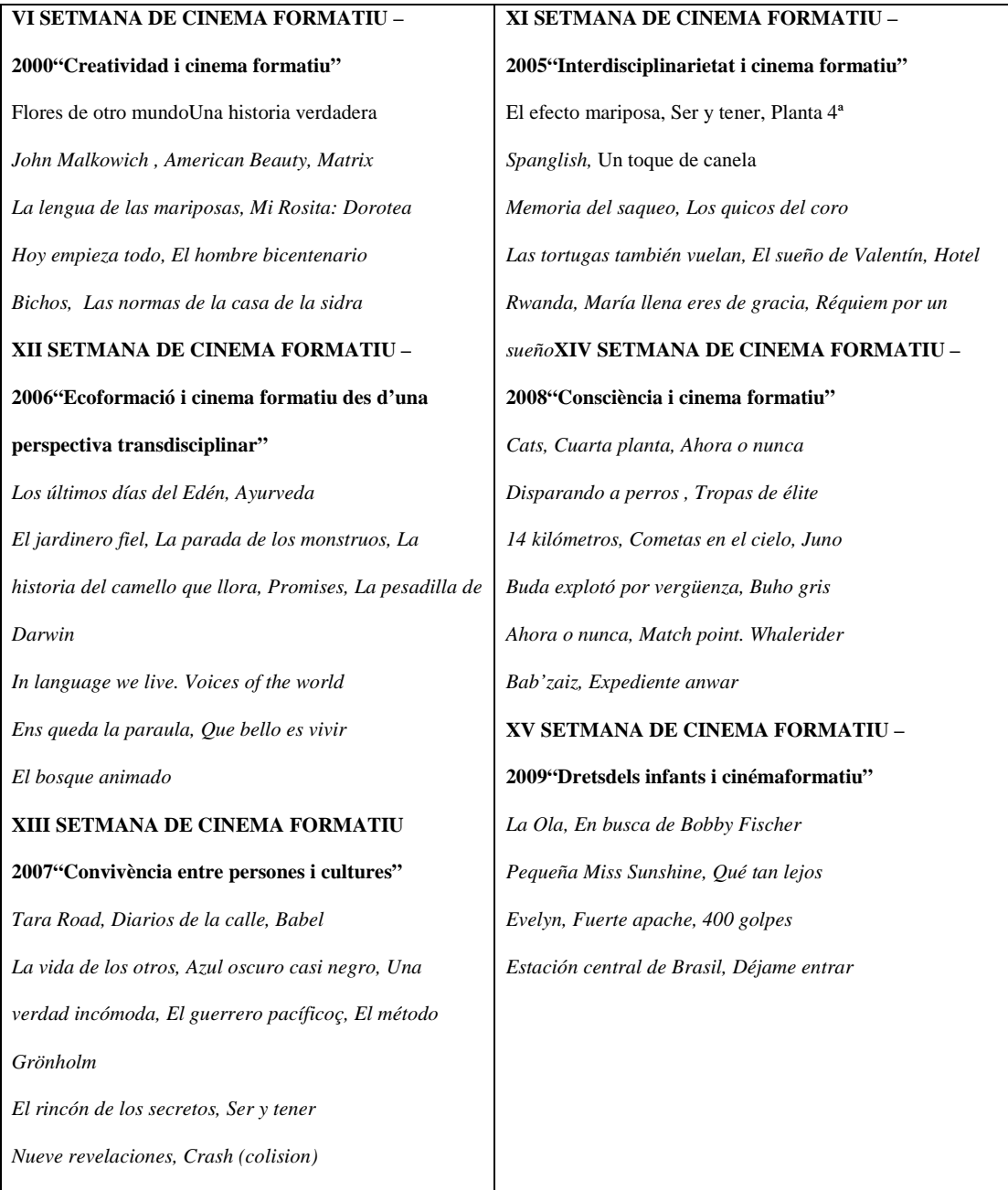

Fecha de recepción: 23-03-2014

Fecha de evaluación: 23-05-2014

Fecha de aceptación: 16-06-2014 
Píxel-Bit. Revista de Medios y Educación. No 46. Enero 2015. ISSN: 1133-8482. e-ISSN: 2171-7966. doi: http://dx.doi.org/10.12795/pixelbit.2015.i46.06 